\title{
The Effect and Complication of Botulinum Toxin Type A Injection with Serial Casting for the Treatment of Spastic Equinus Foot
}

\author{
Sook Joung Lee, M.D., In Young Sung, M.D., Ph.D., Dae Hyun Jang, M.D., \\ Jin Hwa Yi, M.D., Jin Ho Lee, P.T., Ju Seok Ryu, M.D. ${ }^{1}$
}

\begin{abstract}
Department of Rehabilitation Medicine, Asan Medical Center, University of Ulsan College of Medicine, Seoul 138-736,
${ }^{1}$ CHA Bundang Medicine Center, CHA University, Seongnam 463-712, Korea
\end{abstract}

Objective To identify the effect of serial casting combined with Botulinum toxin type A (BTX-A) injection on spastic equinus foot.

Method Twenty-nine children with cerebral palsy who had equinus foot were recruited from the outpatient clinic of Rehabilitation Medicine. The children were divided into 2 groups, one of which received serial casting after BTX-A injection, and the other which only received BTX-A injection. Serial casting started 3 weeks after the BTX-A injection, and was changed weekly for 3 times. Spasticity of the ankle joint was evaluated using the modified Ashworth scale (MAS), and the modified Tardieu scale (MTS). Gait pattern was measured using the physician's rating scale (PRS).

Results The degree of ankle dorsiflexion and the MAS improved significantly until 12 weeks following the BTX-A injection in the serial casting group $(\mathrm{p}<0.001)$, while the BTX-A injection-only group improved until 6 weeks following injection $(\mathrm{p}<0.05)$. The combined group showed a significantly greater increase in the degree of dorsiflexion compared to the BTX-A injection-only group at post-injection weeks 6 and $12(\mathrm{p}<0.05)$. Three children (11.5\%) suffered from foot ulcers as a complication caused by the serial casting.

Conclusion Our study demonstrated that the effect of BTX-A injection with serial casting was superior and lasted longer than the effect of BTX-A injection only in patients with spastic equinus foot. We therefore recommend BTX-A injection with serial casting for the treatment of equinus foot. However, physicians must also consider the possible complications associated with serial casting.

Key Words Cerebral palsy, Equinus foot, Botulinum toxin type A, Serial casting

Received September 16, 2010; Accepted December 11, 2010

Corresponding author: In Young Sung

Department of Rehabilitation Medicine, Asan Medical Center, University of Ulsan College of Medicine, 388-1, Pungnap-2 dong, Songpa-gu, Seoul 138-040, Korea

Tel: +82-2-3010-3792, Fax: +82-2-3010-6964, E-mail: iysung@amc.seoul. $\mathrm{kr}$

Copyright () 2011 by Korean Academy of Rehabilitation Medicine

\section{INTRODUCTION}

Equinus foot is a musculoskeletal complication often seen in patients with cerebral palsy and may cause limitation of activities such as the walking function. ${ }^{1,2}$ Equinus foot can be treated through physical therapy, such as stretching and muscle strengthening exercises, by antispastic drugs, BTX-A injection, ankle-foot orthoses 
and serial casting, or by surgery, such as archilles tendon elongation. Among these treatments, BTX-A injection and serial casting have minimum side effects compared to drug therapy, which may cause CNS-related side effects, such as cognitive disorders and sleepiness. Also, BTX-A injection and serial casting are localized and reversible treatments compared to surgery. ${ }^{3}$

Botulinum toxin type A is widely used to treat equinus foot by acting on acetylcholine receptors in the neuromuscular junction. The toxin irreversibly inhibits the release of acetylcholine from the pre-synaptic membrane and paralyzes muscles by blocking the neurotransmission pathway. ${ }^{4}$ Two to three days after the BTX-A injection, spasticity is reduced; maximum effects occur in the second week, and the effect continues for 3 to 6 months. ${ }^{3,4}$ Short leg casts are used to treat eqinus foot deformity by maintaining a long-term tonic stretch in muscles to increase elasticity in muscle-ligaments parts, and to increase the number of sarcolemma in muscle fibers. ${ }^{5}$ Various studies regarding the use of BTX-A injection followed by serial casting for treatment of spastic equinus foot have been published abroad. ${ }^{6-17}$ However, casting after injection is not yet widely used in Korea, therefore further studies on clinical outcomes and side effects are needed. This study aimed to determine the effects and complications caused by BTX-A injection followed by serial casting.

\section{MATERIALS AND METHODS}

\section{Participants}

Patients who met the following criteria participated in the study: 1) children with spastic cerebral palsy in the Asan Medical Center, Department of Rehabilitation Medicine 2) admitted from November 2008 to March 2009, and from November 2009 to February 2010 3) able to walk on their own 4) equinus gait (toe walking) 5) no record of surgery or BTX-A injection in recent 12 months. Patients incapable of walking, children with dyskinetic type, such as athetoid and ataxic type, or those who have skin problems due to casting could not participate in this study.

\section{Methods}

After the process was explained to the parents/caretakers and was approved by them, children who received the
BTX-A injection and were eligible to participate in the study received casting. Patients who received BTX-A injection only and had a similar ankle joint angle, spasticity, and gait pattern with children who received casting, were chosen for the injection only group. The patients participating in the study were divided into 2 groups: 1) patients in the injection with casting group received BTX-A injection followed by casting 2) patients in the injection group only received BTX-A injection.

To assess patients' motor function, a Gross motor function classification system (GMFCS), Gross motor function measure (GMFM), and a Functional mobility scale (FMS) were used.

For BTX-A injection, Dysport ${ }^{\circledR}$ (Ipsen, Wrexham, United Kingdom) was used, and 1 doctor in the department of rehabilitation medicine conducted the study. The doctor decided the injection site to be in the medial and lateral gastrocnemius muscles after examination, and 12 to 18 $\mathrm{IU} / \mathrm{kg}$ of BTX-A was injected, depending on a patient's weight.

Three weeks after BTX-A injection, patients received their first short leg casting using the Fibrograss walking cast (NEAL CAST ${ }^{\circledR}$, BLTEH, Chuncheon, Korea). This was done weekly for 3 weeks. The ankle joint angle, spasticity, and skin condition were assessed every time. Fibergrass walking casts were applied with the ankle in maximal passive dorsiflexion (Fig. 1). Short leg casting was applied by 1 experienced physical therapist.

Both the injection and cast group, and the injection only group received physical therapy including ankle stretching before and after injection, once per week, for 30 minutes, for 12 weeks. However, patients in the injection and cast group could not perform dorsiflexion exercises while they were in their casts for 3 weeks, but rather performed weight bearing exercises.

The effect of the treatment was assessed by measuring changes in the degree of spasticity and gait pattern, before, 3, 6, and 12 weeks after treatment. The change in the degree of ankle joint spasticity was measured using the Modified Ashworth scale (MAS) and the Modified Tardieu scale (MTS). In MTS, Rl is defined as the joint angle after fast stretch, and R2, the maximum joint angle after slow stretch. ${ }^{18}$ The difference between R1 and R2, defined as the dynamic component (R2-R1), is used to assess spasticity after motor point blocks in children with cerebral palsy. ${ }^{19}$ To compare soleus and gastrocnemius 

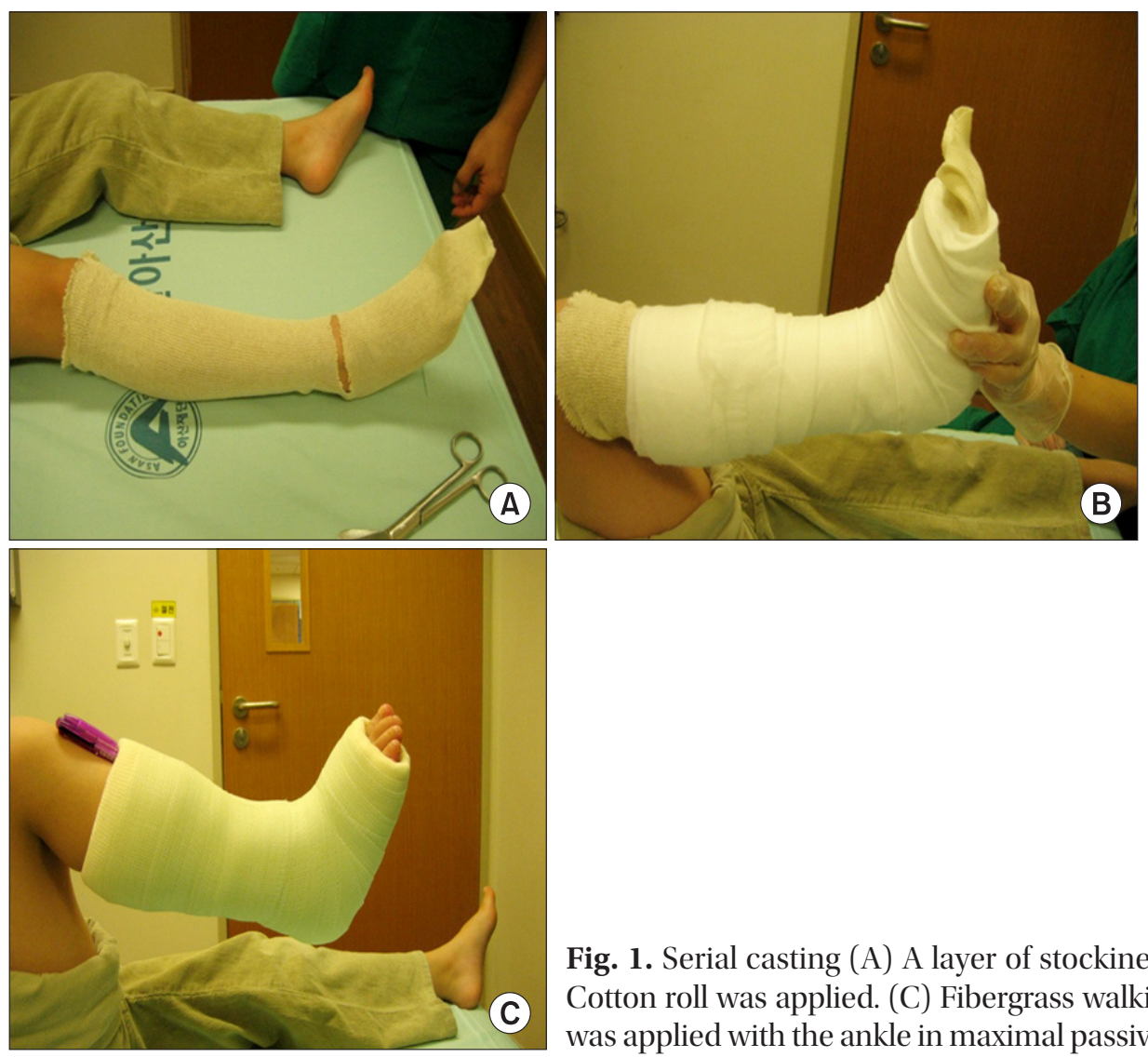

Fig. 1. Serial casting (A) A layer of stockinette was applied over foot and calf. (B) Cotton roll was applied. (C) Fibergrass walking cast (NEAL CAST ${ }^{\circledR}$, BLTEH, Korea) was applied with the ankle in maximal passive dorsiflexion.

muscles, we measured R1 and R2 of ankle joints when knees were bent and straightened.

Physician's rating scale (PRS) was used for quantitative assessment of patients' gait pattern..$^{20}$ PRS consists of 6 categories including gait pattern, ankle position during stance, foot position during heel strike, knee joint angle during stance, shoulder angle when walking, and walking speed. Each category is rated from 0 to 3 , and the total score ranges from 0 to 14 points. The higher the score, the more mature and stable the gait pattern.

To determine if the treatment had side effects, such as a reduction in thigh muscles and pressure ulcers, thigh measurements were taken and patients were checked for skin problems.

SPSS 14.0 for Windows was used for statistical analysis. The Friedman test was used to determine the changes before and after treatment, and the Mann-Whitney U test was used to compare the effectiveness of treatments in the 2 groups. The level for statistical significance was p-value less than 0.05 , and Bonferroni was used as a post hoc test. Each category was paired and the Wilcoxon signed-rank test was performed 6 times; before injection, after injection, and 3, 6, and 12 weeks after injection. The level for statistical significance in the post hoc test was $0.05 / 6 \fallingdotseq 0.0083$.

\section{RESULTS}

Over 9 months, a total number of 86 patients received BTX-A injection, and 72 of them were eligible to participate in the study. The procedure of serial casting was explained to parents/caretakers, and when they provided consent, 26 patients were enrolled into an injection with casting group, and received serial casting, and 17 other patients who showed similar ankle joint angle and spasticity were enrolled into an injection only group. Follow-up was not possible for 5 patients from the injection only group, and 6 patients from the injection with casting group. Also, 3 patients from the injection with casting group suffered pressure ulcers during the serial casting procedure and had to stop treatment.

Follow-up assessments were made, when possible, for a period of 12 weeks. Twelve patients ( 8 males, 4 females) from the injection only group and 17 patients (13 males, 
4 females) from the injection with casting group were assessed. There were no significant difference in their motor functions regarding cerebral palsy, degree of spasticity, or the amount of BTX-A injected (Tables 1, 2). No patients showed symptoms of fever, seizure or anaphylaxis.

Change in ankle joint spasticity was determined in the 2 groups (Tables 3,4 ). The MTS scale in the injection with casting group improved until 12 weeks after injection

Table 1. General Characteristics of Subjects

\begin{tabular}{lccl}
\hline & $\begin{array}{c}\text { Injection with } \\
\text { casting group } \\
(\mathbf{n}=17)\end{array}$ & $\begin{array}{c}\text { Injection } \\
\text { only group } \\
(\mathbf{n}=\mathbf{1 2})\end{array}$ & p-value \\
\hline Age (yr) & $5.8 \pm 2.9$ & $4.3 \pm 1.7$ & 0.482 \\
$\begin{array}{l}\text { Gender (number) } \\
\text { Male/Female }\end{array}$ & $13 / 4$ & $8 / 4$ & \\
$\begin{array}{l}\text { Type of CP (number) } \\
\text { Unilateral/ Bilateral }\end{array}$ & $13 / 4$ & $10 / 2$ & \\
\hline GMFCS & $1.1 \pm 0.3$ & $1.0 \pm 0$ & 0.073 \\
\hline GMFM & $89.7 \pm 6.8$ & $93.7 \pm 6.0$ & 0.084 \\
\hline FMS & 6 & 6 & 1.0 \\
\hline $\begin{array}{l}\text { Body weight } \\
\text { Dysport dose } \\
\text { (IU/Kg/extremity) }\end{array}$ & $21.2 \pm 7.7$ & $19.0 \pm 6.6$ & 0.576 \\
\hline Val & $17.1 \pm 8.3$ & $14.7 \pm 6.5$ & 0.552 \\
\hline
\end{tabular}

Values: mean \pm standard deviation, CP: Cerebral palsy, GMFCS: Gross motor function classification system, GMFM: Gross motor function measure, FMS: Functional mobility scale

p-value by Mann-Whitney U test and was statistically significant. In the injection only group, conditions improved until 6 weeks after injection, but the treatment appeared less effective after 12 weeks. $\mathrm{R} 2-\mathrm{R} 1$, defined as the dynamic component, decreased for 3 weeks after injection, but increased on the sixth week after casting (Fig. 2). R1 increased during the time periods before and 3 weeks after injection, whereas R2 increased more than $\mathrm{R} 1$ when patients received casting from week 3 to week 6 . In the injection only group, the dynamic component decreased until week 6 , and the

Table 2. Baseline Evaluation of Spasticity on Subjects

\begin{tabular}{lrrr}
\hline & $\begin{array}{c}\text { Injection with } \\
\text { casting group } \\
(\mathbf{n}=17)\end{array}$ & $\begin{array}{c}\text { Injection } \\
\text { only group } \\
(\mathbf{n}=12)\end{array}$ & \\
& & & \\
\hline MTS & & & \\
\hline R1 of ADF with KE & $-5.7 \pm 3.8$ & $-4.4 \pm 3.2$ & 0.108 \\
R2 of ADF with KE & $-0.5 \pm 4.6$ & $0.7 \pm 5.2$ & 0.441 \\
\hline R1 of ADF with KF & $2.3 \pm 6.4$ & $3.8 \pm 5.5$ & 0.448 \\
R2 of ADF with KF & $6.0 \pm 5.5$ & $8.9 \pm 5.4$ & 0.373 \\
MAS & $1.7 \pm 0.3$ & $1.5 \pm 0.4$ & 0.901 \\
\hline PRS & $7.9 \pm 3.5$ & $8.2 \pm 3.4$ & 0.895 \\
Circumference $(\mathrm{cm})$ & $21.4 \pm 0.9$ & $25.6 \pm 4.5$ & 0.074 \\
\hline
\end{tabular}

Values are mean \pm standard deviation

MTS: Modified Tardieu scale, R1: Degree of while fast stretch, R2: Degree of while slow passive stretch, ADF: Ankle dorsiflexion, KE: Knee extension, KF: Knee flexion, MAS: Modified Ashworth scale, PRS: Physician's rating scale

p-value by Mann-Whitney U test

Table 3. Changes on Botulinum Toxin A Injection with Casting Group $(\mathrm{n}=17)$

\begin{tabular}{lrrrrc}
\hline & Baseline & Post inj 3 wks & Post inj 6 wks & Post inj 12 wks & p-value \\
\hline MTS & & & & & \\
R1 of ADF with KE & $-5.7 \pm 3.8$ & $-1.3 \pm 3.2^{\dagger}$ & $0.7 \pm 1.0^{\ddagger, \pi}$ & $1.0 \pm 2.1^{\S}$ & $<0.01^{*}$ \\
\hline R2 of ADF with KE & $-0.5 \pm 4.6$ & $4.0 \pm 7.1^{\dagger}$ & $8.7 \pm 4.1^{\dagger, \pi}$ & $9.0 \pm 3.4^{\S}$ & $<0.01^{*}$ \\
R1 of ADF with KF & $2.3 \pm 6.4$ & $5.2 \pm 4.5^{\dagger}$ & $7.5 \pm 3.0^{\dagger, \pi}$ & $7.3 \pm 3.0^{\S}$ & $0.012^{*}$ \\
\hline R2 of ADF with KF & $6.0 \pm 5.5$ & $9.8 \pm 8.0^{\dagger}$ & $14.5 \pm 6.1^{\dagger, \pi}$ & $15.9 \pm 4.2^{\S}$ & $<0.01^{*}$ \\
\hline MAS & $1.7 \pm 0.3$ & $1.3 \pm 0.3^{\dagger}$ & $1.2 \pm 0.7^{\dagger, \pi}$ & $1.2 \pm 0.3^{\S}$ & $0.001^{*}$ \\
\hline PRS & $7.9 \pm 3.5$ & $10.1 \pm 3.6^{\dagger}$ & $11.3 \pm 2.4^{\dagger}$ & $11.3 \pm 2.4^{\S}$ & $0.001^{*}$ \\
\hline Cir. $(\mathrm{cm})$ & $21.4 \pm 0.9$ & $20.9 \pm 1.5$ & $20.5 \pm 1.8^{\dagger}$ & $19.7 \pm 2.0$ & $<0.01^{*}$ \\
\hline
\end{tabular}

Values: mean \pm standard deviation

MTS: Modified Tardieu scale, R1: Spastic catch, R2: Passive range of motion, ADF: Ankle dorsiflexion, KE: Knee extension, KF: Knee flexion, MAS: Modified Ashworth scale, Cir: Circumference

${ }^{*} \mathrm{p}<0.05$ by Freidman test, Post hoc test, ${ }^{\dagger} \mathrm{p}<0.0083$ significant difference between baseline and post injection 3 wks, ${ }^{\ddagger} \mathrm{p}<0.0083$ significant difference between baseline and post injection $6 \mathrm{wks},{ }^{8} \mathrm{p}<0.0083$ significant difference between baseline and post injection $12 \mathrm{wks},{ }^{\pi} \mathrm{p}<0.0083$ significant difference between post injection $3 \mathrm{wks}$ and $6 \mathrm{wks}$ 
Table 4. Changes on Botulinum Toxin A Injection Only Group (n=12)

\begin{tabular}{|lccccc}
\hline & Baseline & Post inj $\mathbf{3}$ wks & Post inj $\mathbf{6}$ wks & Post inj 12 wks & p-value \\
\hline MTS & & & & & \\
\hline R1 of ADF with KE & $-4.4 \pm 3.2$ & $0.6 \pm 5.3^{\dagger}$ & $1.8 \pm 3.8^{+, \pi}$ & $1.1 \pm 2.5^{\S}$ & $<0.01^{*}$ \\
\hline R2 of ADF with KE & $0.7 \pm 5.2$ & $4.8 \pm 7.6^{\dagger}$ & $6.2 \pm 6.4^{\dagger}$ & $5.8 \pm 3.7^{\S}$ & $<0.01^{*}$ \\
R1 of ADF with KF & $3.8 \pm 5.5$ & $7.4 \pm 8.0$ & $8.9 \pm 7.7$ & $7.8 \pm 6.2$ & 0.448 \\
\hline R2 of ADF with KF & $8.9 \pm 5.4$ & $12.4 \pm 8.5^{\dagger}$ & $14.2 \pm 6.9^{\dagger}$ & $13.8 \pm 4.2^{\S}$ & $0.02^{*}$ \\
\hline MAS & $1.5 \pm 0.4$ & $1.1 \pm 0.6$ & $1.0 \pm 0.7$ & $1.1 \pm 0.2$ & 0.07 \\
\hline PRS & $8.2 \pm 3.4$ & $10.7 \pm 2.7^{\dagger}$ & $10.7 \pm 2.7^{\dagger}$ & $10.3 \pm 3.5^{\S}$ & $0.03^{*}$ \\
\hline Cir. $(\mathrm{cm})$ & $25.6 \pm 4.5$ & $25.0 \pm 6.4$ & $24.9 \pm 5.7$ & $24.7 \pm 4.6$ & 0.533 \\
\hline
\end{tabular}

Values: mean \pm standard deviation

MTS: Modified Tardieu scale, R1: Spastic catch, R2: Passive range of motion, ADF: Ankle dorsiflexion, KE: Knee extension, KF: Knee flexion, MAS: Modified Ashworth scale, PRS: Physician's rating scale

${ }^{*} \mathrm{p}<0.05$ by Freidman test, Post hoc test, ${ }^{\dagger} \mathrm{p}<0.0083$ significant difference between baseline and post injection 3 wks, ${ }^{7} \mathrm{p}<0.0083$ significant difference between baseline and post injection $6 \mathrm{wks},{ }^{8} \mathrm{p}<0.0083$ significant difference between baseline and post injection $12 \mathrm{wks},{ }^{\top} \mathrm{p}<0.0083$ significant difference between post injection $3 \mathrm{wks}$ and 6 wks

A

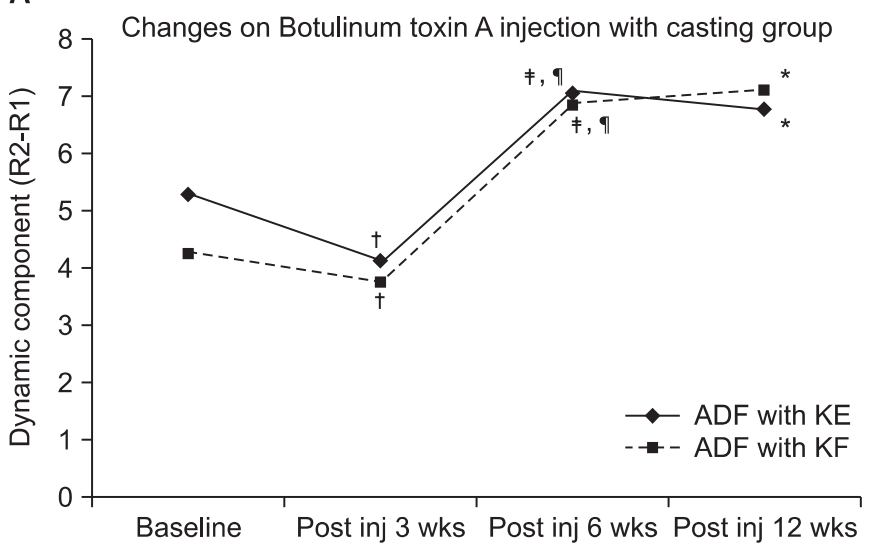

B

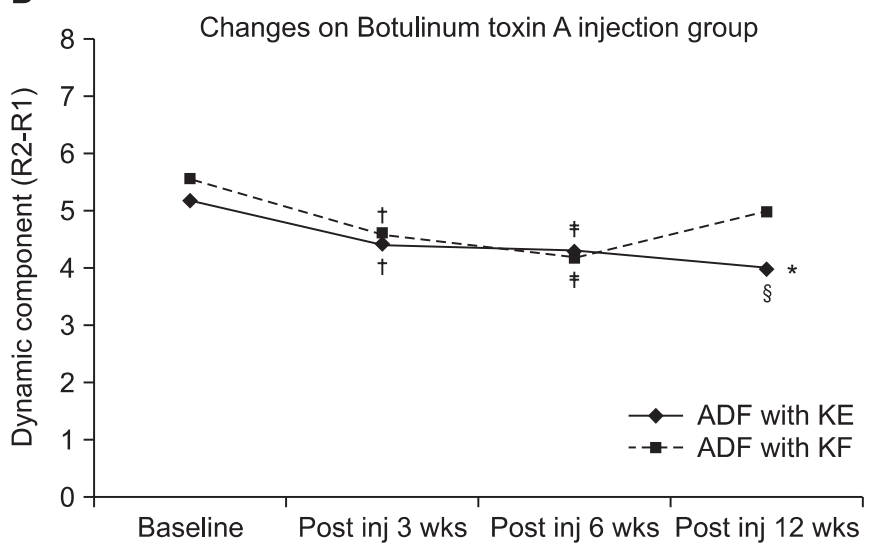

Fig. 2. Changes of dynamic component in both groups, (A) Changes in Botulinum toxin A injection with casting group. (B) Changes in Botulinum toxin A injection group

${ }^{*} \mathrm{p}<0.05$ by Freidman test, Post hoc test, ${ }^{\dagger} \mathrm{p}<0.0083$ significant difference between baseline and post injection 3 wks, ${ }^{*} \mathrm{p}<0.0083$ significant difference between baseline and post injection $6 \mathrm{wks},{ }^{\$} \mathrm{p}<0.0083$ significant difference between baseline and post injection 12 wks, ${ }^{\pi} \mathrm{p}<0.0083$ significant difference between post injection 3 wks and 6 wks.

increase in $\mathrm{R} 1$ was greater than in $\mathrm{R} 2$ in weeks 3 and 6 . To determine the difference between BTX-A injection and casting treatment, the ankle joint angle before treatment was compared to 1) ankle joint angle 3 weeks after BTX-A injection, and 2) ankle joint angle 6 weeks after casting in the injection with casting group. No significant change was found in ankle joint angles before and 3 weeks after treatment in both R1 and R2. However, R2 change before and 6 weeks after treatment in the injection with casting group was significantly greater than in the injection only group (Fig. 3).
MAS, used to evaluate spasticity of the ankle joint, decreased for 12 weeks in the injection with casting group. In the injection only group, however, MAS decreased for 6 weeks, but showed an increase on the 12th week. PRS, used to measure gait pattern improved significantly in both groups after BTX-A injection. Also, in the injection with casting group, PRS improved after serial casting (Tables 3, 4).

Three patients (11.5\%) experienced heel pressure ulcers due to casting and had to stop treatment. All 3 patients suffered from Grade II pressure ulcers; 1 patient did 
A

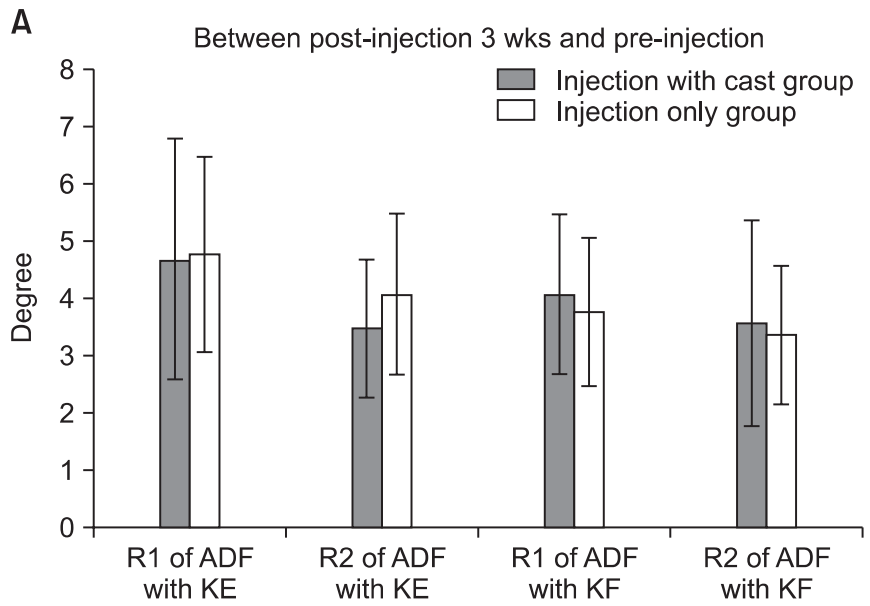

B

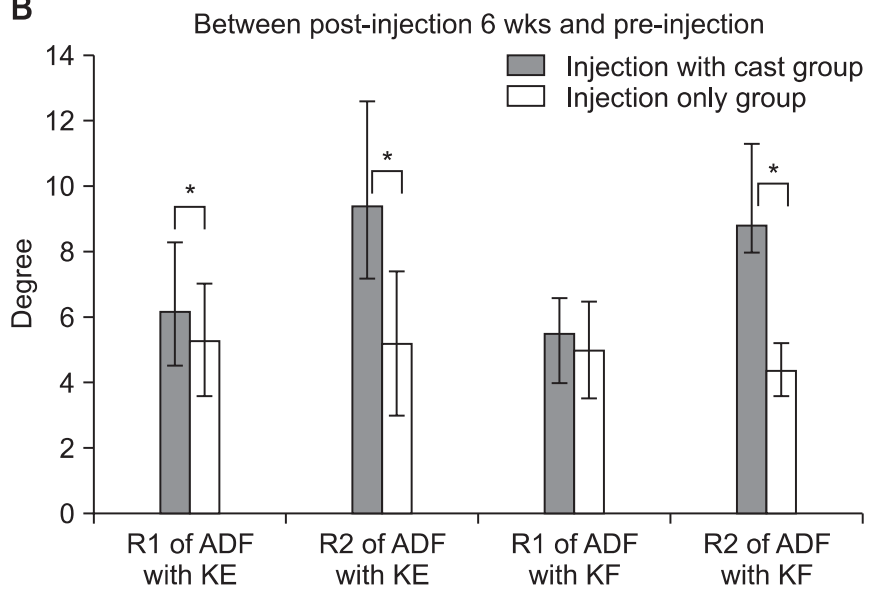

Fig. 3. Changes between post \& pre-injection, (A) Changes between post-injection 3 weeks and pre-injection, (B) Changes between post-injection 6 weeks and pre-injection. The changes were larger for $\Delta \mathrm{R} 2$ degree in the injection with cast group than the injection only group. ${ }^{*} \mathrm{p}<0.05$ by Mann-Whitney U test.

not express discomfort, but pressure ulcers were found during a weekly cast change, and the patient had to stop treatment. The other 2 patients expressed discomfort after receiving casting, and refused to put weight on the leg with the cast. Therefore, these patients' casts were removed within a week, and pressure ulcers were found. No other skin problems were found, including contact dermatitis due to Stockinette. A cotton roll, fibroglass walking cast was used for casting. Most patients who received casting experienced calf muscle atrophy. When calf measurements of the patients in the injection with casting group were taken 12 weeks after injection, the results showed a $-1.7 \pm 1.9 \mathrm{~cm}$ change compared to the measurements taken at the beginning of treatment. The change was relatively large compared to the results from the injection only group $(-1.0 \pm 1.2)$, and was statistically significant $(\mathrm{p}<0.01)$.

\section{DISCUSSION}

Many studies on BTX-A injection and serial casting as a treatment for equinus gait have been conducted (Table 5). From the late 1990s to 2000, after comparing BTX-A injection and casting treatment for 2 to 3 months, Corry et al. ${ }^{7}$, Flett et al. ${ }^{8}$, Houltram et al. ${ }^{9}$ published studies arguing that greater changes in the of ankle joint angles were observed and effects of the treatment lasted longer when patients received BTX-A injection rather than casting.

From the early 2000s, studies were conducted in which both treatments were used. Booth et al. ${ }^{10}$ compared 2 groups: 1) the first group received casting every week, 7-10 days after BTX-A injection, until the ankle dorsiflex angle was $\left.20^{\circ}, 2\right)$ the second group received casting every week until the ankle dorsiflex angle was $20^{\circ}$. Results showed that it took a relatively shorter amount of time for the patients in the first group to have their ankle dorsiflex angle become $20^{\circ}$, and their ankle joint conditions improved faster. Bottos et al. ${ }^{16}$ and Park et al. ${ }^{21}$ compared 2 groups: 1 ) the first group only received BTX-A injection, 2 ) the second group was put in a cast for 3 weeks after BTX-A injection. The second group showed greater reduction in spasticity and greater increase in walking speed.

However, Kay et al. ${ }^{11}$ argued that casting is more effective than BTX-A injection in improving ankle angle. Robert et al. compared 2 groups: 1 ) the first group received casting every 2 weeks, 1 to 3 weeks after injection, until the ankle dorsiflex angle was $5^{\circ}, 2$ ) the second group only received casting every 2 weeks, until the ankle dorsiflex angle was $5^{\circ}$. The changes in the ankle joint angles and spasticity in the second group were greater in the $12^{\text {th }}$ month, compared to the changes seen in the injection with casting group. The results also showed that spasticity recurred in months 6,9 , and 12 in the injection with casting group. Glanzman et al. ${ }^{15}$ compared the effects of 3 different treatments in a chart analysis study: 1) BTX-A injection, 2) casting, 3) BTX-A injection with casting. Results showed that casting was more effective than BTX-A injection, and that there was no difference 
Table 5. Comparison of Recent Studies

\begin{tabular}{|c|c|c|c|c|}
\hline Study & Sample size & Design & Method & Conclusion summary \\
\hline Corry et al., $1998^{7}$ & $\mathrm{n}=20$ & RCT & $\begin{array}{l}\text { BTX injection } \\
\text { vs. casting }\end{array}$ & $\begin{array}{l}\text { BTX-A efficacy was similar to that of } \\
\text { serial casting. There were fewer side } \\
\text { effects in the BTX-A group. }\end{array}$ \\
\hline Fllett et al., $1999^{8}$ & $\mathrm{n}=20$ & RCT & $\begin{array}{l}\text { BTX injection } \\
\text { vs. casting }\end{array}$ & $\begin{array}{l}\text { BTX-A injections were of similar } \\
\text { efficacy to serial fixed plaster casting } \\
\text { in improving dynamic calf tightness in } \\
\text { ambulant children. Parents consistently } \\
\text { favored BTX-A and highlighted the } \\
\text { inconvenience of serial casting. }\end{array}$ \\
\hline $\begin{array}{l}\text { Houltram et al., } \\
2001^{9}\end{array}$ & $\begin{array}{l}\text { Combined } \\
\text { several } \\
\text { articles }\end{array}$ & $\begin{array}{l}\text { Evidence } \\
\text { based } \\
\text { economic } \\
\text { evaluation }\end{array}$ & $\begin{array}{l}\text { BTX injection } \\
\text { vs. casting }\end{array}$ & $\begin{array}{l}\text { BTX-A can be considered a valuable } \\
\text { and cost-effective treatment in the } \\
\text { conservative management of equinus } \\
\text { due to calf spasticity in children with } \\
\text { cerebral palsy. }\end{array}$ \\
\hline Booth et al., $2003^{10}$ & $\mathrm{n}=30$ & $\begin{array}{l}\text { Retrospective } \\
\text { review of } \\
\text { record }\end{array}$ & $\begin{array}{l}\text { BTX vs. BTX injection } \\
\text { with serial casting, } \\
\text { casting started } 7-10 \text { days } \\
\text { after injection, changed } \\
\text { weekly until ADF }>20^{\circ}\end{array}$ & $\begin{array}{l}\text { Using serial casting in conjunction with } \\
\text { BTX-A may achieve range of motion } \\
\text { s goals in less time than serial casting } \\
\text { alone. }\end{array}$ \\
\hline Bottos et al., $2003^{16}$ & $\mathrm{n}=10$ & RCT & $\begin{array}{l}\text { BTX vs. BTX injection } \\
\text { with casting, casting } \\
\text { applied immediately } \\
\text { after injection for } 3 \\
\text { weeks, total } 1 \text { times }\end{array}$ & $\begin{array}{l}\text { BTX-A reduces spasticity and improves } \\
\text { functional performance in standing } \\
\text { and walking; association with casting } \\
\text { provides more marked and enduring } \\
\text { results. }\end{array}$ \\
\hline Kay et al., $2004^{11}$ & $\mathrm{n}=23$ & RCT & $\begin{array}{l}\text { BTX with serial casting } \\
\text { vs. serial casting; casting } \\
\text { started } 1-3 \text { weeks after } \\
\text { injection, changed every } \\
2 \text { weeks until ADF }>5^{\circ}\end{array}$ & $\begin{array}{l}\text { Serial casting alone is preferable for the } \\
\text { treatment of fixed equines contractures } \\
\text { in children with cerebral palsy. }\end{array}$ \\
\hline $\begin{array}{l}\text { Glanzman et al., } \\
2004^{15}\end{array}$ & $\mathrm{n}=55$ & $\begin{array}{l}\text { Retrospective } \\
\text { analysis }\end{array}$ & $\begin{array}{l}\text { BTX vs. casting vs. } \\
\text { combined treatment }\end{array}$ & $\begin{array}{l}\text { Casting demonstrated a significantly } \\
\text { more robust impact on range of motion } \\
\text { than BTX-A alone. }\end{array}$ \\
\hline $\begin{array}{l}\text { Desloovere et al., } \\
2001^{14}\end{array}$ & $\mathrm{n}=34$ & RCT & $\begin{array}{l}\text { Casting after BTX } \\
\text { injection vs. casting } \\
\text { before injection }\end{array}$ & $\begin{array}{l}\text { More pronounced benefits, mainly in } \\
\text { the proximal joints, were seen for the } \\
\text { children who were casted after } \\
\text { injections as compared to the children } \\
\text { who were casted before injections. }\end{array}$ \\
\hline $\begin{array}{l}\text { Newman et al., } \\
2007^{17}\end{array}$ & $\mathrm{n}=12$ & RCT & $\begin{array}{l}\text { Delayed ( } 4 \text { weeks later) } \\
\text { vs. immediate (same } \\
\text { day) serial casting after } \\
\text { BTX injection }\end{array}$ & $\begin{array}{l}\text { There is a clear benefit in delaying serial } \\
\text { casting after the injection of botulinum } \\
\text { toxin in the recurrence of spasticity at } \\
\text { the gastrocnemius. }\end{array}$ \\
\hline Park et al., $2010^{21}$ & $\mathrm{n}=38$ & RCT & $\begin{array}{l}\text { Serial casting after BTX } \\
\text { injection vs. BTX, } \\
\text { casting started } \\
\text { immediately after } \\
\text { injection, changed } \\
\text { weekly for } 3 \text { times }\end{array}$ & $\begin{array}{l}\text { Serial casting application after BTX-A } \\
\text { injection can enhance the benefits of } \\
\text { BTX-A injection in children with } \\
\text { cerebral palsy. }\end{array}$ \\
\hline
\end{tabular}

BTX: Botulinum toxin, RCT: Randomized controlled trial, ADF: Ankle dorsiflexion 
between casting and injection with casting. Therefore, Glanzman et al. argued that casting was more effective than BTX-A injection for improving ankle dorsiflex angle. Fifty-five patients participated in the study, and it was a retrospective chart analysis, but there was no control group and the study was not blinded. Therefore, only changes in ankle joint angles were assessed and whether there was improvement in function is unclear.

There have been many studies in which various combinations of injection and casting were tested. Desloovere et al. ${ }^{14}$ compared an injection after casting group, and a casting after injection group, and concluded that casting after injection was more effective.

Newman et al. ${ }^{17}$ compared 2 groups: 1) the first group received serial casting immediately after injection, 2) the second group received casting 4 weeks after injection. Six months later, the ankle angle in the second group improved significantly and none of the patients in the group expressed pain, whereas children in the first group expressed pain.

Although BTX-A injection and serial casting treatment have been studied for a while, there are still no guidelines. Therefore, even though the effectiveness of the treatment was shown in several studies conducted abroad, not many studies regarding side effects of casting have been published in Korea. Consequently, researchers adopted methods considered most effective: 1) researchers perform serial casting 3 weeks after BTX-A injection, 2) patients receive casting every week for 3 weeks, 3) ankles are put in maximum dorsiflexion during recasting, 4) thigh measurements are taken before and after treatment to determine side effects, 5) patients receive weekly serial casting and are checked for pressure ulcers or skin problems.

In this study, the patients were divided into a BTX-A injection only group, and an injection with casting group. Results showed greater improvement in the ankle joint angle, and greater reduction in spasticity in the injection with casting group, which is consistent with studies conducted earlier. ${ }^{10,15-17}$

We assume that the injection with casting group showed improvement because it was easier to induce ankle joint angle change through casting when BTX-A injection was in effect. Also, casting could have caused larger and longer lasting changes in the ankle joint angle. R1 increased more than R2 3 weeks after BTX-A injection, therefore the dynamic component decreased. Rl indicates the degree of muscle spasticity, ${ }^{22}$ therefore the results obtained are consistent with other studies. ${ }^{19,23,24}$ However, 3 to 6 weeks after casting in the injection with casting group, $\mathrm{R} 2{ }^{22}$ increased more than $\mathrm{R} 1$, and the dynamic component also increased (Figs. 2, 3). This shows that casting maintains muscles in tonic stretch to increase elasticity and to effect changes in characteristics of muscle-ligament parts. ${ }^{5}$

Other studies rarely mention BTX-A and casting complications. One of the side effects following casting was the loss of calf muscles. Patients in casts were encouraged to put weight on their legs wearing splints, but not enough weight must have been applied. Parents/ caretakers also said that patients either refused to walk after casting, or used the leg without the cast to walk. We assume that 3 weeks of casting inhibited muscle contraction and therefore caused muscle atrophy. To enhance the effect of treatment and to minimize muscle atrophy, patients must perform weight bearing and isometric exercises. Other side effects include pressure ulcers, and 3 patients participating in this study experienced pressure ulcers, and therefore could not receive casting for 3 weeks and had to stop treatment. These 3 patients were children with cerebral palsy who had linguistic problems and difficulties expressing themselves. Therefore, patients must be checked for disabilities, such as linguistic problems and intellectual disabilities.

We recommended casting to 72 patients over 9 months, but only 26 children received casting. We assume not many children participated in the study because most patients were school aged children, and leg casts might slow down movements and cause bullying. Also, because warm weather from late spring to early autumn could cause skin problems such as sweating, eczema, and pressure ulcers, studies were usually conducted in the winter.

\section{CONCLUSION}

Compared to the injection only group, the ankle joint angles improved and lasted longer in the injection with casting group. Also, MTS showed that BTX-A injection and casting affected $\mathrm{R} 1$ and $\mathrm{R} 2$ respectively, therefore the treatments contributed in different ways to improve ankle 
joint conditions. We recommend BTX-A injection with casting when treating equinus gait, but side effects must be taken into consideration. Participants must be chosen carefully, checked for skin problems during serial casting, and perform weight bearing and isometric exercises.

\section{REFERENCES}

1. Bax M, Goldstein M, Rosenbaum P, Leviton A, Paneth N, Dan B, Jacobsson B, Damiano D. Proposed definition and classification of cerebral palsy, April 2005. Dev Med Child Neurol 2005; 47: 571-576

2. Bax MC. Terminology and classification of cerebral palsy. Dev Med Child Neurol 1964; 6: 295-297

3. Goldstein EM. Spasticity management: an overview. J Child Neurol 2001; 16: 16-23

4. Huang W, Foster JA, Rogachefsky AS. Pharmacology of botulinum toxin. J Am Acad Dermatol 2000; 43: 249259

5. Gajdosik RL. Passive extensibility of skeletal muscle: review of the literature with clinical implications. Clin Biomech (Bristol, Avon) 2001; 16: 87-101

6. Cosgrove AP, Corry IS, Graham HK. Botulinum toxin in the management of the lower limb in cerebral palsy. Dev Med Child Neurol 1994; 36: 386-396

7. Corry IS, Cosgrove AP, Duffy CM, McNeill S, Taylor TC, Graham HK. Botulinum toxin A compared with stretching casts in the treatment of spastic equinus: a randomised prospective trial. J Pediatr Orthop 1998; 18: 304-311

8. Flett PJ, Stern LM, Waddy H, Connell TM, Seeger JD, Gibson SK. Botulinum toxin A versus fixed cast stretching for dynamic calf tightness in cerebral palsy. J Paediatr Child Health 1999; 35: 71-77

9. Houltram J, Noble I, Boyd RN, Corry I, Flett P, Graham HK. Botulinum toxin type A in the management of equinus in children with cerebral palsy: an evidencebased economic evaluation. Eur J Neurol 2001; 8 Suppl 5: 194-202

10. Booth MY, Yates CC, Edgar TS, Bandy WD. Serial casting vs combined intervention with botulinum toxin A and serial casting in the treatment of spastic equinus in children. Pediatr Phys Ther 2003; 15: 216220

11. Kay RM, Rethlefsen SA, Fern-Buneo A, Wren TA, Skaggs DL. Botulinum toxin as an adjunct to serial casting treatment in children with cerebral palsy. J Bone Joint Surg Am 2004; 86-A: 2377-2384

12. Koman LA, Mooney JF 3rd, Smith BP, Goodman A, Mulvaney T. Management of spasticity in cerebral palsy with botulinum-A toxin: report of a preliminary, randomized, double-blind trial. J Pediatr Orthop 1994; 14: 299-303

13. Kelly B, MacKay-Lyons MJ, Berryman S, Hyndman J, Wood E. Assessment protocol for serial casting after botulinum toxin a injections to treat equinus gait. Pediatr Phys Ther 2008; 20: 233-241

14. Desloovere K, Molenaers G, Jonkers I, De Cat J, De Borre L, Nijs J, Eyssen M, Pauwels P, De Cock P. A randomized study of combined botulinum toxin type A and casting in the ambulant child with cerebral palsy using objective outcome measures. Eur J Neurol 2001; 8 Suppl 5: 75-87

15. Glanzman AM, Kim H, Swaminathan K, Beck T. Efficacy of botulinum toxin A, serial casting, and combined treatment for spastic equinus: a retrospective analysis. Dev Med Child Neurol 2004; 46: $807-811$

16. Bottos M, Benedetti MG, Salucci P, Gasparroni V, Giannini S. Botulinum toxin with and without casting in ambulant children with spastic diplegia: a clinical and functional assessment. Dev Med Child Neurol 2003; 45: 758-762

17. Newman CJ, Kennedy A, Walsh M, O'Brien T, Lynch B, Hensey O. A pilot study of delayed versus immediate serial casting after botulinum toxin injection for partially reducible spastic equinus. J Pediatr Orthop 2007; 27: 882-885

18. Tardieu G, Tardieu C, Colbeau-Justin P, Lespargot A. Muscle hypoextensibility in children with cerebral palsy: II. Therapeutic implications. Arch Phys Med Rehabil 1982; 63: 103-107

19. Fosang AL, Galea MP, McCoy AT, Reddihough DS, Story I. Measures of muscle and joint performance in the lower limb of children with cerebral palsy. Dev Med Child Neurol 2003; 45: 664-670

20. Koman LA, Brashear A, Rosenfeld S, Chambers H, Russman B, Rang M, Root L, Ferrari E, Garcia de Yebenes Prous J, Smith BP, et al. Botulinum toxin type a neuromuscular blockade in the treatment of equinus foot deformity in cerebral palsy: a multicenter, openlabel clinical trial. Pediatrics 2001; 108: 1062-1071 
21. Park ES, Rha DW, Yoo JK, Kim SM, Chang WH, Song $\mathrm{SH}$. Short-term effects of combined serial casting and botulinum toxin injection for spastic equinus in ambulatory children with cerebral palsy. Yonsei Med J 2010; 51: 579-584

22. Mackey AH, Walt SE, Lobb G, Stott NS. Intraobserver reliability of the modified Tardieu scale in the upper limb of children with hemiplegia. Dev Med Child Neurol 2004; 46: 267-272
23. Boyd RN, Pliatsios V, Starr R, Wolfe R, Graham HK. Biomechanical transformation of the gastroc-soleus muscle with botulinum toxin A in children with cerebral palsy. Dev Med Child Neurol 2000; 42: 32-41

24. Rhim SY, Kim MJ, Han SH. The effects of dilution volume of botulinum toxin A on the spasticity of children with cerebral palsy. J Korea Acad Rehab Med 2008; 32: 294-299 